\title{
Optimalisasi Penerapan MLC (Maritime Labour Convention) di Atas Kapal KM Bukit Siguntang
}

\author{
Arleiny $^{\text {a }}$, Dwi Anggreni Wulandari ${ }^{\text {b* }}$, Indah Ayu Johanda Putric, Muhamad Imam \\ Firdaus $^{d}$, Muhammad Nadjib Lawangi ${ }^{\mathrm{e}}$ \\ a,b,c,d,e Politeknik Pelayaran Surabaya \\ aEmail: arleiny@poltekpel-sby.ac.id, \\ b*Email: wulandaridwianggraeni@gmail.com \\ 'Email: mindahayu@poltekpel-sby.ac.id,
}

\begin{abstract}
ABSTRAK
Indonesia merupakan negara kepulauan dengan jumlah 17.508 pulau. Oleh karena itu, sarana pengangkutan melalui laut sangat dibutuhkan untuk menunjang arus perdagangan dalam menjangkau wilayah antar pulau satu dengan lainnya melalui perairan baik nasional maupun internasional. Tujuan penelitian ini adalah untuk mengetahui optimalisasi penerapan MLC (Maritime Labour Convention) di atas kapal dan mengetahui pengaruh penerapan MLC (Maritime Labour Convention) bagi kesejahteraan para pelaut. Penelitian ini termasuk dalam penelitian kualitatif. Metode pengambilan data dalam penelitian ini adalah dengan survei dan wawancara. Hasil penelitian ini adalah menunjukkan bahwa MLC 2006 tentang kesejahteraan pelaut di atas kapal KMBukit Siguntang sudah diterapkan dengan baik, namun waktu istirahat belum optimal sehingga perlu diperhatikan pengoptimalannya. Penerapan MLC 2006 berpengaruh besar terhadap kesejahteraan pelaut di atas kapal.
\end{abstract}

Kata Kunci: optimalisasi, MLC, kualitatif

\begin{abstract}
Indonesia is an archipelagic country with 17,508 islands. Therefore, transportation by sea is very much needed to support trade flows in reaching areas between islands with one another through national and international waters. The purpose of this study was to determine the optimization of the implementation of the MLC (Maritime Labor Convention) on ships and to determine the effect of the implementation of the MLC (Maritime Labor Convention) for the welfare of seafarers. The data collection method is survey and interview methods. This research is included in qualitative research. The results of this study indicate that the 2006 MLC regarding the welfare of seafarers on board KM Bukit Siguntang has been implemented well, but the rest time is not optimal so it is necessary to pay attention to its optimization. The implementation of the 2006 MLC had a major impact on the welfare of seafarers on board.
\end{abstract}

Keywords: optimization, $M L C$, qualitative

\section{PENDAHULUAN}

Tenaga kerja yang bekerja di kapal harus mendapatkan hak dan kewajiban seperti halnya mereka yang bekerja di perusahaan pada umumnya. Hak yang diterima mereka yang bekerja di atas kapal umumnya lebih banyak. Hal ini mengingat sifat khusus pekerjaan yang dilakukan relatif lebih berat
(Demirel dan Bayer, 2016). Awak kapal atau crew kapal adalah orang yang bekerja atau dipekerjakan di atas kapal oleh pemilik atau operator kapal untuk melakukan tugas di atas kapal sesuai dengan jabatan yang tercantum dalam buku sijil (UU RI Nomor 17 Tahun 2008 tentang Pelayaran). Oleh karena itu analisa dan penerapan MLC (Maritime 
Labour Convention) di atas kapal harus benar diterapkan untuk meningkatkan kesejahteraan para pelaut melalui ketentuan-ketentuan yang dapat diterima secara mendunia (Jiankai, 2020). Hal yang sebenarnya terkandung dalam materi penerapan MLC di atas kapal (Meitmann, 2015), (Carey, 2017) adalah sebuah pengetahuan yang diberikan kepada cadet sebagai calon perwira untuk mempersiapkan diri sebagai Perwira di atas kapal agar memiliki pedoman untuk memiliki haknya sebagai seorang pelaut agar mendapatkan kesejahteraan di atas kapal (Doyle, et al., 2016).

\section{METODE}

Penelitian ini merupakan penelitian deskriptif kualitatif. Penelitian dilakukan dengan menggambarkan kondisi apa adanya terhadap subjek penelitian, tanpa memberi perlakuan atau manipulasi. Pengambilan data dilakukan dengan surveii dan wawancara kepada perwira dan awak kapal KM Bukit Siguntang.

Penelitian ini penulis khususkan dalam hal permasalahan yang ditemui penulis yaitu adanya tidak terlaksananya MLC di atas kapal KM Bukit Siguntang seperti waktu istirahat yang kurang optimal. Dengan permasalahanpermasalahan yang ditemui penulis dalam penelitian, penulis menggunakan metode deskriptif supaya mempunyai makna yang sama dan alami seperti data yang diteliti.

\section{HASIL DAN PEMBAHASAN}

Penulis melakukan penelitian pada tanggal 26 September 2020 hingga 26 Juni 2021 di atas kapal penumpang milik PT. Pelayaran Nasional Indonesia. Data mengenai kapal tersebut adalah sebagai berikut.

1. Deadweight tonasse 3686 TDW

2. GT. 14.701 ton

3. Panjang kapal 146,5 Meter

4. Lebar 23,40 meter
Berdasarkan pengalaman yang penulis alami di atas kapal selama praktiik layar tidak banyak $\mathrm{ABK}$ yang memahami apa itu MLC (Maritime Labour Convention) (International Labour Organization, 2006). Pada saat melakukan wawancara kepada Anak Buah Kapal bagaimana optimalisasi penerapan MLC (Maritime Labour Convention) (Fotteler, Bygvraa, \& Jensen, 2020), (İRTEM, BAYAR, \& ALKAN, 2015) di atas kapal ada sebagian yang mengetahui namun masih sangat minim. Kebanyakan para Anak Buah Kapal sudah merasa puas dengan fasilitas dan kebijakan diatas KMBukit Siguntang. Penerapan MLC (Maritime Labour Convention) di atas KMBukit Siguntang yang dinaungi oleh PT. Pelayaran Nasional Indonesia dapat di katakan telah diterapkan dengan baik meskipun ada beberapa hal yang harus diperhatikan serta ditingkatkan.

Hal terkait kontrak kerja jika dilihat dari segi perlindungan hukum tenaga kerja non organik belum memberikan kepastian hukum yang pasti mengenai perlindungan hukum kaitannya dengan resiko bahaya di laut (Slišković \& Penezić, 2016), (The Australian Maritime Safety Authority, 2020).

Untuk mengenai upah kerja/gaji di KMBukit Siguntang di berikan hak upah sesuai dengan jabatan atau golongan. Hasil dari wawancara penulis terhadap salah satu perwira di atas kapal disebutkan bahwa gaji telah sesuai dengan MLC 2006. Ada beberapa tunjangan yang didapatkan oleh awak kapal seperti tunjangan pendidikan, THR pada saat hari raya dengan diberikan penuh gaji penuh dan ada beberapa tunjangan lainnya.

Dalam hal cuti seluruh crew KMBukit Siguntang melaksanakan cuti wajib setiap 3 bulan sekali, sehingga terhitung 3 bulan dinas di laut sementara 1 bulan cuti wajib.

Adapun hal yang tidak sesuai dengan pokok isi MLC 2006 yaitu waktu 
istirahat yang belum bisa dikatakan sesuai. Berdasarkan yang penulispenulis amati waktu istirahat yang tidak menentu di karenakan beberapa pelabuhan yang di singgahi jaraknya tidak begitu jauh maka waktu tempuh perjalanan yang singkat membuat istirahat tidak begitu leluasa karena pada saat kapal sandar seluruh crew KM Bukit Siguntang memiliki tugas masing-masing sesuai tanggung jawabnya yang harus dilakukan ketika kapal sandar. Beberapa hal lain yang membuat waktu istirahat tidak sesuai isi pokok pada MLC 2006 yaitu kondisi muatan yang tidak menentu sehingga mengakibatkan keterlambatan kapal berangkat yang mengakibatkan jadwal untuk tiba tidak sesuai kemudian pihak kapal harus menyesuaikan waktu kembali supaya kembali menjadi sesuai jadwal.

Tabel 1. Hasil Wawancara Dengan Mualim 2

\begin{tabular}{|l|l|l|}
\hline No. & \multicolumn{1}{|c|}{ Pertanyaan } & \multicolumn{1}{c|}{ Jawaban } \\
\hline 1. & $\begin{array}{l}\text { Bagaimana } \\
\text { Optimalisasi } \\
\text { Penerapan } \\
\text { MLC di atas } \\
\text { kapal? }\end{array}$ & $\begin{array}{l}\text { Menurut } \\
\text { respondenResponden } \\
\text { optimalisasi } \\
\text { penerapan MLC di } \\
\text { kapal ini sudah } \\
\text { memenuhi syarat dan } \\
\text { diterapkan sangat } \\
\text { baik dengan } \\
\text { makanan yang layak } \\
\text { serta berkualitas, } \\
\text { ako-modasi yang } \\
\text { sudah memadahi dan } \\
\text { mungkin masih } \\
\text { banyak lainnya }\end{array}$ \\
\hline 2. & $\begin{array}{l}\text { Bagaimana } \\
\text { pengaruh dari } \\
\text { penerapan } \\
\text { MLC } \\
\text { (Maritime } \\
\text { Labour } \\
\text { Convention }) \text { di } \\
\text { atas kapal } \\
\text { terhadap } \\
\text { kesejahteraan } \\
\text { para pelaut? }\end{array}$ & $\begin{array}{l}\text { Sangat berpengaruh } \\
\text { karena membuat } \\
\text { para pelaut semakin } \\
\text { giat dalam bekerja, } \\
\text { lebih fokus dan } \\
\text { merasa nyaman } \\
\text { berada di atas kapal }\end{array}$ \\
\hline
\end{tabular}

Berdasarkan hasil pengolahan data maka penulis menemukan bahwa dalam penerapan MLC (Maritime Labour
Convention) di atas KM Bukit Siguntang beberapa sudah diterapkan dengan baik. Namun ditemukan masalah perihal waktu istirahat yang kurang atau atau tidak sesuai dengan MLC 2006 jam kerja maksimum wajib tidak melebihi 14 jam dalam jangka waktu 24 jam dan jam istirahat minimum tidak kurang dari sepuluh jam dalam waktu 24 jam.

Pada saat kapal sandar seorang mualim I bertanggung jawab atas muatan, kemudian mualim III membantu tugas mualim I dengan mengawasi serta bertanggung jawab muatan berada di palka di mulai dari kapal sandar hingga selesai muatannya semua, biasanya hingga waktu kapal tolak pada pelabuhan berikutnya. Setelah itu mualim III melakukan tugas wajibnya untuk jaga 8 12 berada di anjungan. Pada saat itu kapal tiba sandar jam 01.00 dini hari kemudian tolak untuk pelabuhan berikutnya jam 06.00 , waktu untuk istirahat hanya 2 jam setelah itu melakukan tugas wajibnya kembali dan pelabuhan berikutnya sandar jam 13.00 kemudian harus kembali bekerja untuk bertanggung jawab atas muatan di palka. Jika dihitung dalam 24 jam maka jumlah jam kerja mualim III tersebut yaitu 19 jam dan jam istirahat 5 jam, sehingga dapat dikatakan bahwa jam kerja dan jam istirahat belum sesuai dengan aturan standar bagian keempat kesejahteraan awak kapal pasal 21 tentang jam kerja dan jam istirahat.

Tabel 2. Standar MLC 2006 dan PP Kepelautan

\begin{tabular}{|l|l|}
$\begin{array}{l}\text { STANDAR PP KEPELAUTAN DAN MLC } \\
\text { 2006 }\end{array}$ \\
\hline & $\begin{array}{l}\text { PP Kepelautan Pasal } \\
18 \text { ayat (3) perjanjian } \\
\text { kerja sekurang- } \\
\text { kurangnya memuat } \\
\text { hak-hak pelaut dan } \\
\text { kewajiban pelaut } \\
\text { termasuk hak pemilik } \\
\text { dan kewajiban } \\
\text { perjilik }\end{array}$ \\
\hline
\end{tabular}




\begin{tabular}{|c|c|}
\hline Upah dan GGaji & $\begin{array}{l}\text { PP Kepelautan pasal } \\
22 \text { ayat (2) upah } \\
\text { lembur perjam } \\
\text { dihitung dengan } \\
\text { rumus upah } \\
\text { minimum } 190 \times 1,25 \text {. } \\
\text { Penetapan angka } 190 \\
\text { adalah jumlah jam } \\
\text { kerja dalam } 1 \text { bulan, } \\
1,25 \text { adalah sesuai } \\
\text { konvensi ILO. }\end{array}$ \\
\hline $\begin{array}{c}\text { Jam KKerja dan JJam } \\
\text { IIstirahat }\end{array}$ & $\begin{array}{l}\text { Sn Standar A2.3 } \\
\text { MLC 2006. Jam kerja } \\
\text { tidak lebih dari } 14 \\
\text { jam dalam sehari ( } 24 \\
\text { jam). Jam istirahat } \\
\text { tidak kurang dari } 10 \\
\text { jam dalam } 24 \text { jam. }\end{array}$ \\
\hline Hak CCuti & $\begin{array}{l}\text { PP Kepelautan pasal } \\
24 \text { ayat (1) Hak cuti } \\
\text { tahunan paling lama } \\
20 \text { hari kalender } \\
\text { untuk setiap jangka } \\
\text { waktu } 1 \text { tahun } \\
\text { bekerja, pelaut } \\
\text { memiliki hak cuti } \\
\text { selama } 2,5 \text { hari x } 12 \\
\text { bulan = } 30 \text { hari cuti }\end{array}$ \\
\hline $\begin{array}{l}\text { Akomodasi, } \\
\text { FFasilitas, } \\
\text { MMakanan dan } \\
\text { KKatering }\end{array}$ & $\begin{array}{l}\text { Penempatan, tata } \\
\text { susunan dan } \\
\text { pengaturan serta } \\
\text { hubungan dengan } \\
\text { ruangan lain dari } \\
\text { akomodasi awak } \\
\text { kapal harus } \\
\text { sedemikian rupa } \\
\text { sehingga menjamin } \\
\text { keselamatan awak } \\
\text { kapal yang cukup, } \\
\text { perlindungan } \\
\text { terhadap cuaca dan } \\
\text { air laut dan disekat } \\
\text { dari panas dingin } \\
\text { serta kebisingan dari } \\
\text { ruangan-ruangan } \\
\text { mesin dan ruangan- } \\
\text { ruangan lainnya. } \\
\text { Kemudian makanan } \\
\text { harus memenuhi } \\
\text { jumlah ragam dan } \\
\text { nilai gizi dengan } \\
\text { minimum } 3600 \\
\text { kalori/hari. }\end{array}$ \\
\hline
\end{tabular}

Tabel 3. Perjanjian Kerja Laut di atas Kapal KM Bukit Siguntang

\begin{tabular}{|c|c|}
\hline \multicolumn{2}{|c|}{$\begin{array}{c}\text { Penerapan Perjanjian Kerja Laut dalam } \\
\text { PKL No.Pk 305/9/B PT. Pelayaran } \\
\text { Nasional Indonesia KMBukit Siguntang }\end{array}$} \\
\hline $\begin{array}{c}\text { Perjanjian KKerja } \\
\text { LLaut }\end{array}$ & $\begin{array}{l}\text { Pengangkatan tenaga } \\
\text { kerja organik } \\
\text { dilakukan apabila } \\
\text { seorang tenaga kerja } \\
\text { sudah bekerja minimal } \\
\text { selama } 4 \text { tahun dan } \\
\text { telah memenuhi syarat } \\
\text { untuk diangkat } \\
\text { menjadi tenaga kerja } \\
\text { tetap (Organik) }\end{array}$ \\
\hline Upah dan GGaji & $\begin{array}{l}\text { Perusahaan membayar } \\
\text { gaji kepada kru kapal } \\
\text { pada akhir bulan } \\
\text { dengan mata uang } \\
\text { Indonesia, ditambah } \\
\text { dengan premi, jaminan } \\
\text { sosialsosial, kenaikan } \\
\text { gaji berkala.thr, } \\
\text { tunjangan pendidikan, } \\
\text { jasa } \\
\text { produksi,tunjangan } \\
\text { akhir tahun. }\end{array}$ \\
\hline $\begin{array}{l}\text { Jam Kerja dan } \\
\text { Jam Istirahat }\end{array}$ & $\begin{array}{l}\text { Dinas jaga pelabuhan } \\
\text { anak buah kapal } \\
\text { disesuaikan dengan } \\
\text { kebutuhan sesuai } \\
\text { lamanya kapal } \\
\text { dipelabuhan sesuai } \\
\text { perintah nakhoda. }\end{array}$ \\
\hline Hak CCuti & $\begin{array}{l}\text { Perusahaan } \\
\text { memberlakukan cuti } \\
\text { wajib } 3 \text { bulan sekali, } \\
\text { dengan } 3 \text { bulan dinas } \\
\text { di atas kapal dan } 1 \\
\text { bulan cuti wajib }\end{array}$ \\
\hline $\begin{array}{l}\text { Akomodasi, } \\
\text { FFasilitas, } \\
\text { MMakanan dan } \\
\text { KKatering }\end{array}$ & $\begin{array}{l}\text { Tata letak kamar yang } \\
\text { layak serta fasilitas } \\
\text { yang memadai di atas } \\
\text { kapal sesuai standar } \\
\text { dan mendapatkan } \\
\text { makanan yang } \\
\text { memenuhi kalori yang } \\
\text { dibutuhkan perhari } \\
\text { serta diperhatikan nilai } \\
\text { gizinya. Ruang } \\
\text { rekreasi terdapat } \\
\text { perlengkapan } \\
\text { elektronik seperti } \\
\text { televisii dan memutar } \\
D V D / C D \text { juga } \\
\text { peralatan olahraga } \\
\text { yaitu pingpong }\end{array}$ \\
\hline
\end{tabular}


Tabel 4. Penerapan di Atas Kapal

\begin{tabular}{|c|c|c|}
\hline $\begin{array}{c}\text { Standard } \\
\text { From } \\
\begin{array}{c}\text { Maritime } \\
\text { Labour } \\
\text { Convention } \\
\text { 2006 }\end{array}\end{array}$ & Diterapkan & $\begin{array}{c}\text { Penerapan di atas kapal } \\
\text { Diterapkan }\end{array}$ \\
\hline $\begin{array}{c}\text { Perjanjian } \\
\text { Kerja Laut }\end{array}$ & $\checkmark$ & \\
\hline Upah dan Gaji & $\checkmark$ & \\
\hline $\begin{array}{c}\text { Jam Kerja dan } \\
\text { Jam Istirahat }\end{array}$ & & $\checkmark$ \\
\hline Hak Cuti & $\checkmark$ & \\
\hline $\begin{array}{c}\text { Akomodasi, } \\
\text { Fasilitas, } \\
\text { Makanan dan } \\
\text { Katering }\end{array}$ & $\checkmark$ & \\
\hline
\end{tabular}

\section{SIMPULAN}

Berdasarkan hasil penelitian yang telah dilakukan, maka dapat disimpulkan bahwa dalam penerapan Maritime Labour Convention 2006 tentang kesejahteraan pelaut di atas kapal KM Bukit Siguntang sudah diterapkan dengan baik, namun untuk waktu istirahat belum optimal sehingga perlu diperhatikan. Maka perlunya meningkatkan kesejahteraan para pelaut di atas kapal dengan cara mengoptimalkan penerapan MLC 2006, karena MLC 2006 memiliki pengaruh yang besar terhadap seluruh pelaut.

Setelah penulis melakukan pengamatan dan pembahasan mengenai optimalisasi penerapan MLC (Maritime Labour Convention) di atas kapal KM Bukit Siguntang penulis akan memberikan saran yang sekiranya bermanfaat dan sebagai guna untuk memperbaiki tentang perlindungan dan kesejahteraan pelaut di atas kapal. Saran yang kami berikan adalah perusahaan harus membuat sistem kerja ISF Watchkeeper agar lebih sistematis dalam bekerja dan tertata waktu istirahatnya. Perusahaan juga perlu meningkatkan pengetahuan standardisasi pelaut untuk mendapatkan kenyamanan dalam bekerja dan kesejahteraan yang sesuai. Yang terakhir, mengontrol seluruh kapal dengan memastikan sudah diterapkannya
MLC (Maritime Labour Convention) dengan sesuai aturan yang berlaku atau belum.

\section{DAFTAR PUSTAKA}

Carey, L. (2017). The Maritime Labour Convention, 2006: The Seafarer And The Fisher. ANZ Mar LJ, 31, 14-36.

Demirel, E., and Bayer, D. (2016). A Study On Cost Optimization In The Ship Management. The Second Global Conference on Innovation in Marine Technology and the Future of Maritime Transportation, 24-25 October 2016. Bodrum, Muğla, Turkiye.

Doyle, N., MacLachlan, M., Fraser, A., Stilz, R., Lismont, K., Cox, H., \& McVeigh, J. (2016). Resilience and Well-Being Among Seafarers: Cross-Sectional Study of Crew Across 51 Ships. Int Arch Occup Environ Health.

Fotteler, M. L., Bygvraa, D. A., \& Jensen, O. C. (2020). The Impact Of The Maritime Labor Convention On Seafarers' Working And Living Conditions: An Analysis of Port State Control Statistics. BMC Public Health, 20(1586).

International Labour Organization. (2006). Maritime Labour Convention. Retrieved September 30, 2021, from https://www.ilo.org/global/standa rds/maritime-labour convention/lang\%2 D\%2Den/index.htm.

İrtem, Ş. S., Bayar, S., \& Alkan, G. (2015, December). The Implementation of Maritime Labour Convention in the Ship Management: A Case Study on Risk Management OnBoard. International Journal of Operations and Logistics Management, 4(4), 253-267.

Jiankai, E. C. (2020). The Effectiveness of The Maritime Labour 
Convention's Financial Security

Certificates In Resolving Claims

For Unpaid Seafarers' Wages.

NUS Centre for Maritime Law,

Faculty of Law.

Meitmann, C. A. (2015). Enforcing the Maritme Labour Convention 2006. Diploma Thesis, 15 ETC, Linnaeus University, Kalmar Maritime Academy.

Slišković, A., \& Penezić, Z. (2016). Testing the Associations Between Different Aspects of Seafarers' Employment Contract And Onboard Internet Access and Their Job and Life Satisfaction and Health: Arch Ind Hyg Toxicol.

The Australian Maritime Safety Authority. (2020). A guide to the implementation of the Maritime Labour Convention 2006 in Australia . Australia: AMSA. 